P0-0123 THE INCREASE IN PLASMA SELENIUM IS INDEPENDENTLY ASSOCIATED WITH A BETTER OUTCOME OF CHILDREN WITH ACUTE SYSTEMIC INFLAMMATION

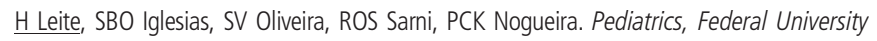
of Sao Paulo, Sao Paulo, Brazil

10.1136/archdischild-2014-307384.789

Background and aims To assess the effects of changes in plasma selenium on the outcome in critically ill children

Methods Plasma selenium concentrations were prospectively measured in 99 children with acute systemic inflammatory response. The exposure variable was defined as the difference between plasma selenium concentrations between the 5th day post admission and the admission to the ICU (delta selenium). Age, malnutrition, red cell GPx-1 activity, serum C-reactive protein, Paediatric Index of Mortality 2 and Paediatric Logistic Organ Dysfunction scores were analysed as covariates for the outcomes. The outcome variables were ventilator-free days, ICUfree days and 28-day mortality. Selenium was given only as part of the enteral diets.

Results Plasma selenium concentrations below the 2.5 percentile for age were found in $72 \%$ and in $59 \%$ of patients on admission and day 5, respectively. Values increased from admission (median $23.4 \mu \mathrm{g} / \mathrm{L}$, interquartile range $12.0-30.8$ ) to 5 th day (median $25.1 \mu \mathrm{g} / \mathrm{L}$, interquartile range $16.0-39.0 ; \mathrm{p}=0.018$ ). After adjustment for confounding factors, a 'delta selenium' increase of $10 \mu \mathrm{g} / \mathrm{L}$ was associated with reductions in ventilator days $(1.4$ days, 95\% C. I. $0.4-2.5 ; \mathrm{p}=0.016$ ), ICU days (1.6 days, $95 \%$ C. I. $0.6-2.6 ; \mathrm{p}<0.002)$, and with decreased 28 -day mortality on univariate model $(\mathrm{p}=0.036)$. The mean daily selenium intake $(6.82 \mu \mathrm{g}$; range 0 to $48.66 \mu \mathrm{g})$ was correlated with the increase in selenium concentrations on day 5 .

Conclusion In children with systemic inflammation, the increase in plasma selenium concentration was independently associated with shorter times of mechanical ventilation and ICU stay. These results raise the question of selenium supplementation in children with critical illness.

\section{PO-0124 FATHERS' KNOWLEDGE AND ATTITUDE TOWARD BREASTFEEDING: A CROSS SECTIONAL STUDY}

J Llamas, A Regal. Pediatrics, University of Santo Tomas Hospital, Metro Manila, Philippines

\subsection{6/archdischild-2014-307384.790}

Objective To determine the breastfeeding knowledge and attitudes of fathers seen at the University of Santo Tomas Hospital.

Design Cross-sectional design

Setting University of Santo Tomas Hospital (USTH)

Participants 156 fathers who were accompanying their wives/ children at the USTH

Findings The outcome of the Iowa Infant Feeding Attitude Scale showed fathers to be generally unbiased whether their child be fed breast milk or milk formula. About $85 \%$ agreed that breast milk is the ideal food for babies, 79\% believed that breastfed babies are healthier than formula fed and 55\% of them do not believe that breast milk lacks iron. About $80 \%$ agreed that it is easily digested, $87 \%$ are aware of the economical value and $57 \%$ agreed of its convenience. Breastfeeding support was noted when $55 \%$ of the fathers would encourage mothers to breastfeed so as not to miss the joys of motherhood, 91\% believed that breastfeeding increased mother-infant bonding. About 57\% do not feel left out whenever the mothers breastfeed.

However, $46.6 \%$ support the decision of their wives to switch to formula feeding once they go back to work, $42 \%$ only find breastfeeding in public to be acceptable and 57\% will not allow breastfeeding to mothers who drink alcohol.

Conclusion In the study although fathers' attitude toward breastfeeding is unbiased towards breastfeeding or formula feeding, the majority of the fathers appreciate breastfeeding and its benefits.

\section{P0-0125 CORRELATION BETWEEN ESOPHAGEAL PH-METRY AND ESOPHAGITIS IN GASTROESOPHAGEAL REFLUX DISEASE}

V Lupu, G Paduraru, A Ignat, G Ciubotariu, S Diaconescu, M Burlea. Pediatrics, "Gr. T. Popa" University of Medicine and Pharmacy, lasi, Romania

\subsection{6/archdischild-2014-307384.791}

Background and aims The study compares the 24 h esophageal pH-metry, used to be considered the "gold diagnosis" for the gastroesophageal reflux, with the esophagitis degree observed at the upper digestive endoscopy.

Material 72 children were included, aged over 4 years old, admitted in a paediatric gastroenterology regional centre in northeast Romania, diagnosed with gastroesophageal reflux disease (GERD) by 24 hours pH-metry (with a positive Boix Ochoa score), which also underwent the upper digestive endoscopy.

Results Out of the 72 children diagnosed with GERD, 47 (65.28\%) had first degree esophagitis and 25 (34.72\%) second degree esophagitis. In GERD associated with second degree esophagitis the Boix Ochoa score is statistically significant higher compared with the GERD associated with first degree esophagitis $(\mathrm{F}=9.76, \mathrm{p}=0.0036,95 \% \mathrm{CI})$.

Conclusions Upper digestive endoscopy performed in patients with gastroesophageal reflux disease shows the constant presence of esophagitis at all patients. There were only first and second degree esophagitis due to the fact that they are young patients with a relative short history of the disease. The correlation tests show a perfect parallel between the $\mathrm{pH}$-metry scores and the endoscopic lesion. The correlation is so accurate that the $\mathrm{pH}$ metry scores can be sufficient to prove the disease and the esophagitis degree, the upper digestive endoscopy being reserved only for the cases that does not respond to the medical treatment or have other complications.

\section{P0-0126 WITHDRAWN}

\section{P0-0127 WITHDRAWN}

\section{P0-0128 INFANT AND YOUNG CHILD FEEDING PRACTICES IN INFANTS RECEIVING SKIN TO SKIN CARE AT BIRTH: A FOLLOW UP OF RANDOMISED COHORT}

${ }^{1}$ SM Nimbalkar, ${ }^{1}$ DV Patel, ${ }^{1}$ DN Patel, ${ }^{1}$ VK Patel, ${ }^{2}$ AS Nimbalkar, ${ }^{3}$ AG Phatak. ${ }^{1}$ Department of Pediatrics, Pramukhswami Medical College, Karamsad, India; ${ }^{2}$ Department of Physiology, Pramukhswami Medical College, Karamsad, India; ${ }^{3}$ Central Research Services, Charutar Arogya Mandal, Karamsad, India

10.1136/archdischild-2014-307384.792 